\title{
Infection of Commercial Laying Hens with Salmonella Gallinarum: Clinical, Anatomopathological and Haematological Studies
}

\begin{tabular}{l} 
- Author(s) \\
\hline Freitas Neto OC \\
Arroyave $\mathrm{W}^{2}$ \\
Alessi $\mathrm{AC}^{3}$ \\
Fagliari JJ \\
Berchieri A \\
\\
1 Post-Graduate student, Faculdade de \\
Ciências Agrarias e Veterinarias, \\
Universidade Estadual Paulista, Jaboticabal, \\
São Paulo, Brazil. \\
2 Professor, Universidad de La Paz, Colombia. \\
3 Professor, Departamento de Patologia \\
Animal, Faculdade de Ciencias Agrárias e \\
Veterinárias, Universidade Estadual Paulista, \\
Jaboticabal, São Paulo, Brazil. \\
4 Professor, Departamento de Clínica e \\
Cirurgia, Faculdade de Ciências Agrárias e \\
Veterinárias, Universidade Estadual Paulista, \\
Jaboticabal, São Paulo, Brazil.
\end{tabular}

Mail Address

OC Freitas Neto

Rua Colombo Berlingieri, 127

Vila Industrial

14.870-000 . Jaboticabal, SP, Brasil

E-mail: oliveirocaetano@yahoo.com.br

Keywords

Fowl typhoid, hematology, laying hens, Salmonella Gallinarum, susceptibility.

\section{Acknowledgments}

The authors thank the helpful assistance of Aparecida Rodrigues, Antonio José dos Santos, Maria Yamazaky, and Francisca Ardisson, from the Pathology Laboratory (UNESP); and of Mr. Eugenio Campos, for assistance with the clinical analyses. Funding from FAPESP and $\mathrm{CNPq}$ enabled the study.

\section{ABSTRACT}

This study aimed at evaluating the susceptibility of commercial laying hens to Salmonella Gallinarum (SG). Two experiments w ere carried using a mutant strain of Salmonella Gallinarum resistant to nalidix acid (SGNAL'). In the first trial, the resistance of birds was evaluated based on clinical signs, faecal shedding, and mortality. It was carried out with six lines of commercial layers being three light white layers, considered to be resistant to SG (W1, W2, W3), and three semi-heavy brown varieties (B1, B2, B3), considered susceptible to SG. Each group contained 15 one-day-old birds. Hens were inoculated in the crop at 5 days of age with $0.2 \mathrm{~mL}$ of SGNALr neat culture. In addition, to each brown variety, a new group of 15 birds was challenged with $0.2 \mathrm{~mL}$ of the same SGNALr culture diluted at $10^{-3}$. At the end of the first experiment, the surviving birds were sacrificed, and microbiological culture of liver and spleen was performed. In the second experiment, white and brown birds were inoculated with neat culture at five days of age. Samples were collected for evaluation of blood parameters and histopathology assessment at $1,3,5,7,9,12$, and 14 days post-infection. The results of the first experiment showed higher resistance of white birds $(p<0.05)$, although there was no uniformity in the responses against fowl typhoid among the birds within these groups. In the second experiment, there were differences between white and brown birds both in blood parameters and in organ lesion intensity.

\section{INTRODUCTION}

Fowl typhoid is caused by Salmonella Gallinarum, and it is a serious systemic disease that affects birds. According to Shivaprasad (2000), fowl typhoid causes clinical signs in young and adult birds, including anorexia, diarrhea, dehydration, weakness, as well as gross and microscopic lesions in organs, such as spleen, liver, ovary, heart etc.

Fowl typhoid has a very complex epidemiology. Birds are mainly contaminated by horizontal route. The contact between healthy and sick birds, cannibalism, and the presence of dead birds, wild birds, and workers contribute for dissemination of Salmonella Gallinarum in flocks (Berchieri, 2000a).

Therefore, Salmonella Gallinarum affects production parameters, resulting in high mortality and lower laying rates, causing economic losses (Pomeroy, 1987; Berchieri, 2000a; Shivaprasad, 2000). Although vaccination programs against this disease have been adopted, fowl typhoid is still reported in Mexico, Central America, South America, Africa, India, and South Korea (Berchieri, 2000a; Shivaprasad, 2000; JiDong et al., 2006).

The know ledge on the resistance mechanisms of birds to this infection is limited. The resistance of some birds to salmonellosis may be related 
Freitas Neto OC, Arroyave W, Alessi AC, Fagliari JJ, Berchieri A
Infection of Commercial Laying Hens with Salmonella Gallinarum: Clinical, Anatomopathological and Haematological Studies to their ability to host the bacteria, and to control bacterial growth inside the cells of the reticuloendothelial system, and also fecal shedding, without eliciting clinical signs. Some studies indicate that resistance to salmonellosis occurs due to a better ability of the phagocytic mononuclear system in restraining infection onset (Qureshi, 1998; Wigley et al., 2002). Nevertheless, doubts still exist whether such efficacy is due to the presence of a high number of phagocytic cells at infection onset, or if the number of cells involved, more than the type of cells, is what really determines the success in clearing up the disease (Qureshi, 1998).

Some studies describe the differences in bird resistance to the infection caused by $S$. Gallinarum (Oliveira et al., 2005; Prince, 1966; Wigley et al., 2002). However, the information provided by such sources are not useful to currently produced birds. The modern poultry industry demands better animal performance, which in turn compromises the immune system of birds, adversely affecting their resistance to diseases. The objectives of the present study were to evaluate layer genetic lines considered to be resistant and susceptible to fowl typhoid, taking into account mortality, fecal shedding, clinical signs, macroscopic and microscopic lesions, as well as to monitor changes in hematological parameters of birds experimentally challenged with $S$. Gallinarum.

\section{MATERIAL AND METHODS}

\section{Inoculum}

In both experiments, birds were challenged using a Salmonella enterica serovar Gallinarum strain resistant to nalidixic acid (SGNalr). The strain was prepared, and kept at the Department of Animal Pathology, Faculdade de Ciências Agrárias e Veterinárias, Universidade Estadual Paulista (FCAVJ-UNESP), according to the methodology described by Smith (1955) and Berchieri et al. (2001).

Bacteria were grow $n$ in nutrient broth, and incubated with shaking at $37^{\circ} \mathrm{C}$ for $24 \mathrm{~h}$. The culture contained approximately $3.3 \times 10^{8}$ colony forming units per milliliter (CFU/mL).

\section{Experiment 1}

One hundred and thirty-five females of six commercial layer genetic lines were obtained at 1 day of age from commercial hatcheries. Three light white (considered to be resistant) and three semi-heavy brown lines (considered to be susceptible to fowl typhoid) were used. Chicks were housed in battery cages with electrical heating, located at the isolating units of the Laboratory of Animal Pathology of the Department of Animal Pathology of FCAVJ-UNESP. Food and water were provided ad libitum. A fast seroagglutination test was performed, and cloacal swabs were taken immediately after the birds arrived in order to confirm that they were free from Salmonella.

Birds were randomly distributed into nine groups. Fifteen birds from light lines $\left(\mathrm{W}_{1}, \mathrm{~W}_{2}\right.$, and $\left.\mathrm{W}_{3}\right)$ were inoculated in the crop at five days of age with $0.2 \mathrm{~mL}$ of SGNal' neat culture $\left(3.3 \times 10^{8} \mathrm{CFU} / \mathrm{mL}\right)$. Each semiheavy variety $\left(B_{1}, B_{2}\right.$, and $\left.B_{3}\right)$ was divided into two groups of 15 birds each. The birds of first one group were inoculated with the neat culture of SGNALr, whereas the birds of the second one group were inoculated with $0.2 \mathrm{~mL}$ of the culture diluted at $10^{-3}$ (approximately $3.3 \times 10^{5} \mathrm{CFU} \mathrm{SGNal} / \mathrm{mL}$ ). Bacteriology tests were performed twice a week using cloacal swabs. The surviving birds were sacrificed at 23 days post-infection, and swab samples were taken from the liver and the spleen. Bacteriological examination of these samples was carried out according to a previously described methodology (Berchieri et al., 2001). Briefly, the swabs were placed in tubes with $2.0 \mathrm{~mL}$ of SeleniteNovobiocin broth (SN), and then streaked onto brilliant green agar with nalidixic acid $(25 \mu \mathrm{g} / \mathrm{mL})$ and Novobiocin $(1 \mu \mathrm{g} / \mathrm{mL})$ (BG Nal Nov). Both the plate and the tube were incubated at $37^{\circ} \mathrm{C}$ for 24 hours. In the absence of growth, new plating was performed from the incubated swab. During the experimental period, clinical signs and mortality were daily recorded.

\section{Experiment 2}

In this experiment, 160 one-day-old male birds were used, belonging to $W_{1}$ (white) and $B_{3}$ (brown) commercial genetic lines. Birds were housed in battery cages with electrical heating, located at the isolation units of the Laboratory of Pathology of FCAVJ-UNESP, and received water and food ad libitum. The absence of Salmonella was confirmed as described above.

Fifty semi-heavy birds and 50 light birds were housed in separate rooms, and challenged with SGNalr at five days of age. They were orally inoculated with $0.2 \mathrm{~mL}$ of neat culture SGNalr in the crop. Thirty birds of each strain were housed separately, and used as noninoculated controls. In order to perform blood analyses and evaluation of gross and microscopic lesions, five birds from each group were randomly selected to collect blood samples and samples of the following organs: brain, cerebellum, heart, lungs, kidney, liver, 
Freitas Neto OC, Arroyave W, Alessi AC, Fagliari JJ, Berchieri A
Infection of Commercial Laying Hens with Salmonella Gallinarum: Clinical, Anatomopathological and Haematological Studies spleen, thymus, bursa of Fabricius, duodenum, and cecal tonsils. The first sampling was performed one day after infection, and then every 48 hours, with a total of seven samplings for light birds and five samplings for semi-heavy birds. Such difference was due to higher mortality presented by the semi-heavy birds. Blood for hematological analyses was also collected 1 day before experimental inoculation.

Blood samples were collected using anticoagulant (0.1 mL heparin/ $\mathrm{mL}$ blood). Globular volume (GV) was determined using microhematocrit method (Jain, 1986), hemoglobin $(\mathrm{Hb})$, according to the cyanomethemoglobin technique (Jain, 1986), and red cell and white cell counts using a Neubauer hemocytometer (Natt \& Herrick, 1952). Differential leukocyte count was performed using blood smears stained according to the Rosenfeld method (Lucas \& Jamroz, 1961). Mean corpuscular hemoglobin (MCH), mean corpuscular hemoglobin concentration ( $\mathrm{CHCM}$ ), and mean corpuscular volume (MCV) were then calculated (Jain, 1986; Lucas \& Jamroz 1961). Albumin concentration (Alb) and the activity of the enzyme aspartate aminotransferase (AST) were determined using commercial kits and a semi-automatic spectrophotometer*, according to bromocresol green and Reitman-Frankel methods, respectively.

Organs were fixed for at least 24 hours in $4 \%$ buffered formaldehyde, $\mathrm{pH} 7.2$, at a ratio of 20:1 (buffer:organ fragment). Fragments were further processed at the Histopathology Laboratory of FCAVJUNESP according to routine methods (Behmer et al., 1976); 4- $\mu \mathrm{m}$ sections were taken and stained with hematoxylin-eosin. The stained sections were analyzed under a light microscope equipped with a digital camera (NICKON ECLIPSE E 200 x COOLPIX 5400)

\section{Statistical analysis}

Chi-square was used to determine differences in mortality among the groups in the first experiment. In the second experiment, the Tukey Studentized Range test (HSD) was used to determine mean, standard deviation, analysis of variance, and the significant differences among groups. In both experiments, the Statistical Analysis System (SAS) software was used to perform the analyses, and differences were considered significant at a $5 \%$ level.

\section{RESULTS}

In the first experiment, serum agglutination test evidenced that the birds were free from Salmonella when they arrived. Higher mortality $(p<0.05)$ was observed in the semi-heavy bird group as compared to the light birds when the neat culture was used as inoculum $\left(3.3 \times 10^{8} \mathrm{CFU} \mathrm{SGNal} / \mathrm{ml}\right)$. On the other hand, there were no significant differences between groups $(p>0.05$ ) when the diluted inoculum was used. M ortality was different $(p<0.05)$ between $W_{1}$ and $W_{3}$ (light lines); mortality rate was $40 \%$ in $\mathrm{W}_{3}$ and $7 \%$ in $\mathrm{W}_{1}$. There was no statistical difference in mortality among semiheavy lines inoculated with neat culture $(p>0.05)$, neither there were differences when diluted culture was used as inoculum. Mortality rate varied between $7 \%$ and $40 \%$ in light birds, and between 40 and $100 \%$ in semi-heavy birds (Table 1).

Bacteriological assessment of feces showed the presence of Salmonella in one semi-heavy bird $\left(B_{3}\right) 7$ days post-inoculation; sampling was performed just before the bird died. At 23 days post-inoculation, SGNal' was isolated from the liver of $5 / 12,4 / 9,2 / 14$ of the resistant $W_{2}, W_{3}$ and $W_{1}$ lines, respectively, whereas only one semi-heavy bird ( $\left.B_{2}\right)$ was positive for SGNalr when neat culture was used $\left(3.3 \times 10^{8} \mathrm{CFU} / \mathrm{mL}\right)$.

Considering the clinical evaluation, light $\mathrm{W}_{2}$ and $\mathrm{W}_{3}$ birds showed signs of disease, such as depression, weakness, loss of appetite, ruffled feathers, dropped

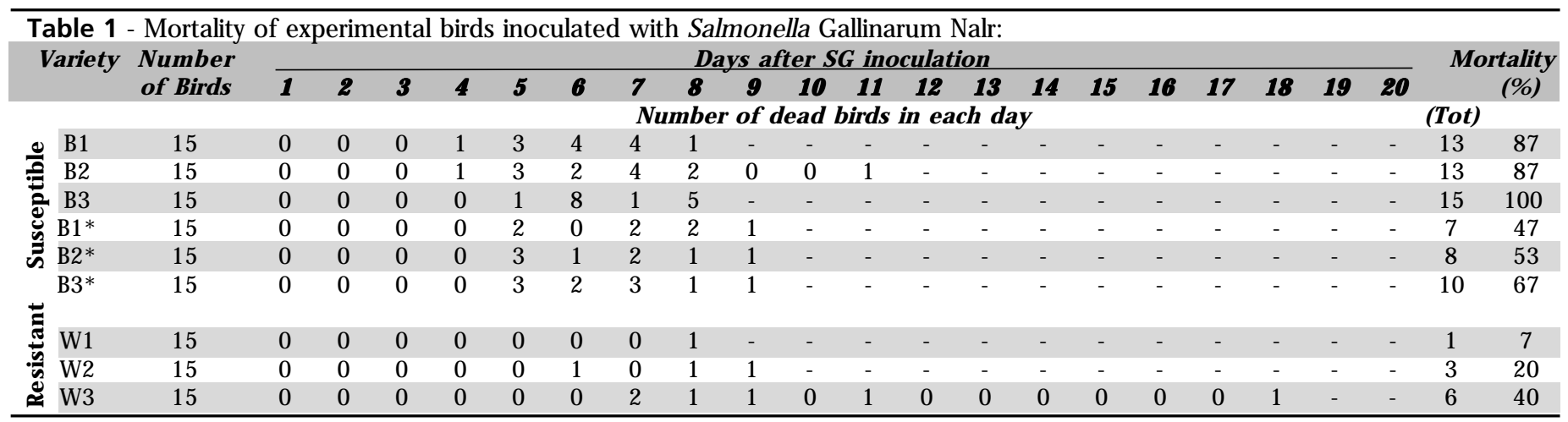

$B 1, B 2$, and B3= semi-heavy brown birds; $W 1, W 2$ and $W 3=$ light white birds: Groups B1, B2, B3, W1, W2 and W3 received $0.2 \mathrm{~mL}$ of culture with $3.3 \times 10^{8}$ CFU SG Nalr $/ \mathrm{mL}$, while B1*, B2* and B3* received $0.2 \mathrm{~mL}$ of the same culture diluted at $10^{-3}$. 
Freitas Neto OC, Arroyave W, Alessi AC, Fagliari JJ, Berchieri A
Infection of Commercial Laying Hens with Salmonella Gallinarum: Clinical, Anatomopathological and Haematological Studies wings, and closed eyes. In addition, these birds presented mortality five days post-inoculation. On the other hand, semi-heavy birds died suddenly at five to seven days post-inoculation, and showed no clinical signs.

In the second experiment, there was no evidence of bacterial infection by serology. As to mortality, no birds died in the control (non-inoculated) and light groups. The number of dead birds in the semi-heavy groups was higher than in the other groups, being nine, nine, and six at days 5, 6, and 7 post-inoculation, respectively.

Gross changes were observed in the organs of semiheavy birds, mainly in the liver, which was larger, with green-yellowish color, and friable. There was also spleen congestion and splenomegaly. There were no evident anatomopathological changes in light birds (Figure 1).

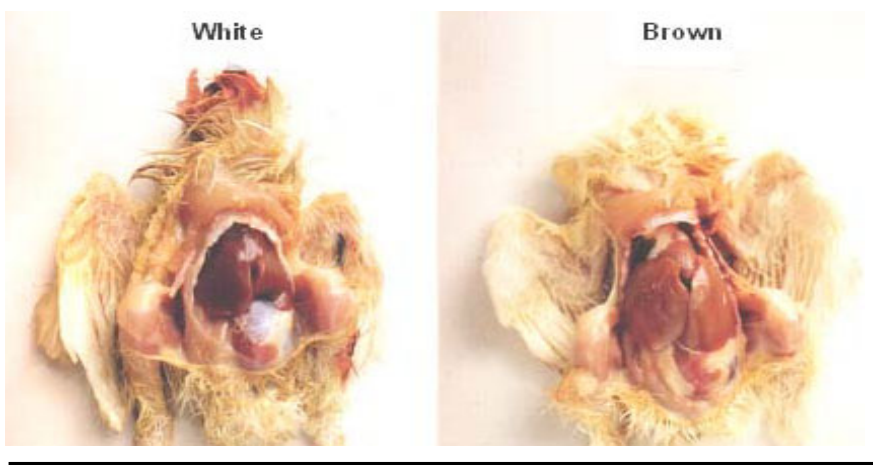

Figure 1 - Gross changes in white (W) and brown birds (B) experimentally infected with SG NaLr.

The most important microscopic changes were observed in the liver, heart, and kidney in both genetic lines (Figures 2, 3, and 4). In semi-heavy birds, the liver presented multifocal necrosis, whereas light birds showed vacuolar degeneration. The heart of semiheavy birds had inflammatory infiltrates with predominantly heterophils; light birds had inflammatory infiltrate with no predominance of polymorph populations. There was an inflammatory reaction with polymorph infiltration in the kidney of semi-heavy birds, but rare polymorphs were seen in the kidney of light birds. The lungs of birds of both lines presented mild inflammatory infiltrate.

As for hematological changes (Table 2), the group of semi-heavy birds presented significant reduction in total red cell count at five and nine days postinoculation as compared to the same group of birds before being inoculated $(p<0.05)$. In light birds, there were no differences in mean values during the experimental period ( $p>0.05)$. For both strains, there were no significant differences in mean hemoglobin concentration values. There were also no significant differences in globular volume, mean corpuscular hemoglobin, mean corpuscular hemoglobin concentration, or in mean corpuscular in either bird strain.
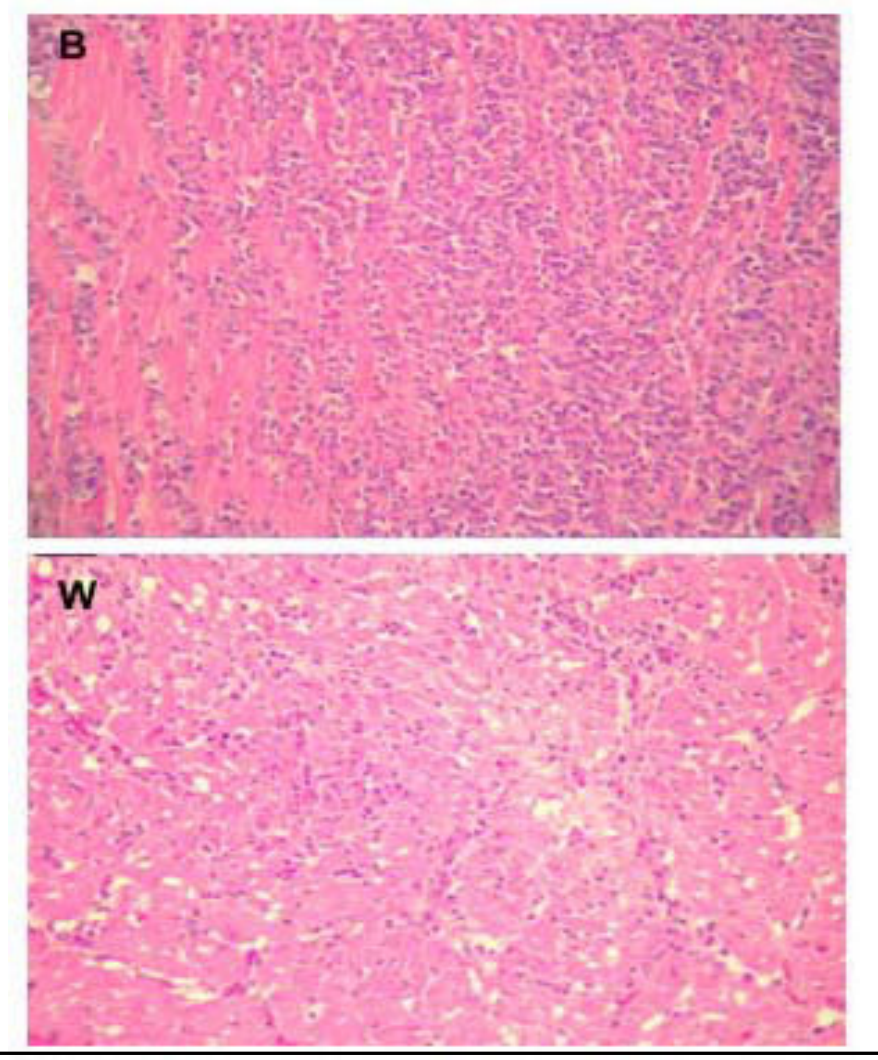

Figure 2 - Photomicrography (40x) of the heart of brown (B) and white birds (W) experimentally challenged with SGNaLr (second experiment). Observed that in the upper picture, the inflammatory reaction is more intensive than in the low er picture.

Serum albumin levels of semi-heavy birds presented no statistical differences during the experiment, but there was a marked decrease five days postinoculation. In light birds, there was a significant increase in albumin values 12 days post-inoculation as compared to the values reported before inoculation (Table 3).

Aspartate aminotransferase enzymatic activity of semi-heavy birds was significantly higher $(p<0.05)$ five days post-inoculation as compared to the mean value previous to inoculation (Table 3 ), whereas there was a significant increase in light birds at 5, 7, 12, and 14 days post-inoculation as compared to the values before inoculation $(p<0.05)$. 

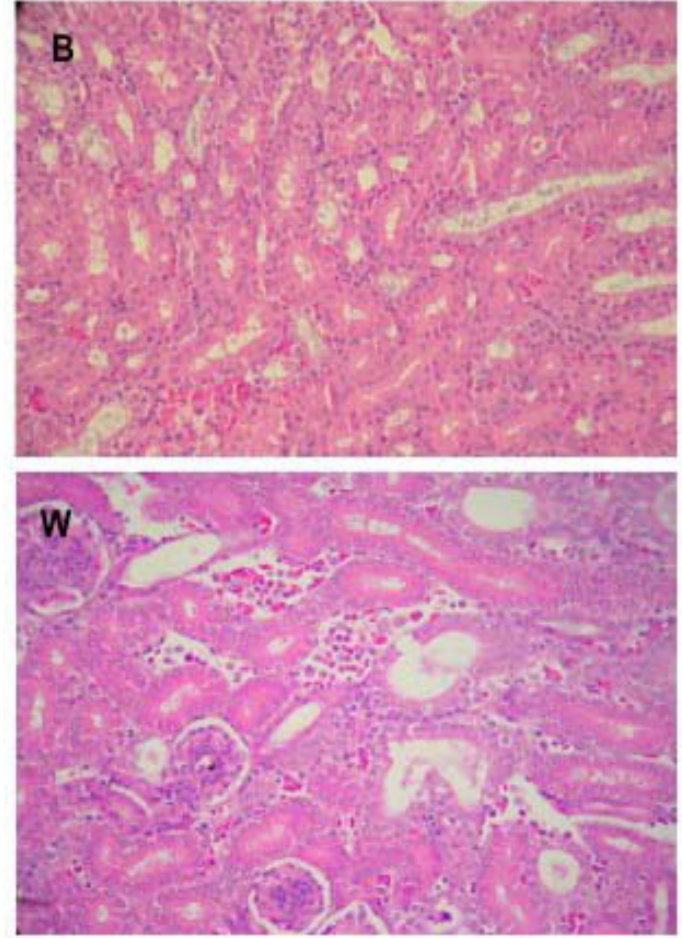

Figure 3 - Photomicrography $(40 \mathrm{x})$ of the kidney of brown (B) and white birds (W) experimentally challenged with SG Nalr. Observe in the upper picture, the intensive inflammatory reaction. In the lower picture, there is less inflammation.
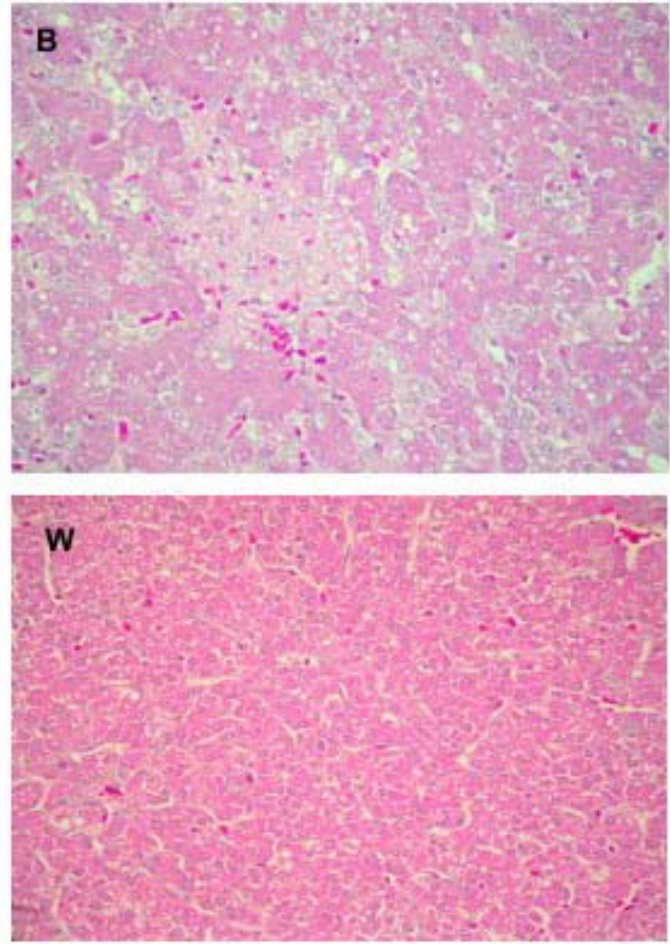

Figure 4 - Photomicrography $(40 \mathrm{x})$ of the liver of brown (B) and white birds (W) experimentally challenged with SG NaLr. See in the upper picture multifocal necrosis of hepatocytes (irreversible lesion). In the lower picture, there is a vacuolar degeneration of hepatocytes (reversible lesion).

\begin{tabular}{|c|c|c|c|c|c|c|c|c|c|c|c|c|}
\hline \multirow{3}{*}{$\begin{array}{l}\text { Days post } \\
\text {-inoculation } \\
\text { (Dpi) }\end{array}$} & \multicolumn{12}{|c|}{ Means of red blood cell counts and some hematological parameters } \\
\hline & \multicolumn{2}{|c|}{$\operatorname{Rc} \times 10^{5} / \mu \mathrm{L}$} & \multicolumn{2}{|c|}{ GV (\%) } & \multicolumn{2}{|c|}{$\mathrm{Hb}(\mathrm{g} / \mathrm{dL})$} & \multicolumn{2}{|c|}{ MCV } & \multicolumn{2}{|c|}{ MCH (pg) } & \multicolumn{2}{|c|}{ MCHC $(g / d L)$} \\
\hline & B & W & B & $\mathbf{W}$ & B & W & B & $\mathbf{W}$ & B & w & B & $\mathbf{W}$ \\
\hline - $1 \mathrm{Dpi}$ & $2074^{B}$ & $2000^{A}$ & $28.00^{\mathrm{A}}$ & $28.4^{\mathrm{A}}$ & $13.07^{\mathrm{A}}$ & $14.47^{\mathrm{A}}$ & $135.88^{\mathrm{A}}$ & $144.93^{\mathrm{A}}$ & $64.20^{\mathrm{A}}$ & $72.78^{\mathrm{A}}$ & $47.00^{\mathrm{A}}$ & $51.42^{\mathrm{A}}$ \\
\hline 1으 Di & $1700^{\mathrm{AB}}$ & $1955^{\mathrm{A}}$ & $26.25^{\mathrm{A}}$ & $29.5^{\mathrm{A}}$ & $13.98^{\mathrm{A}}$ & $14.77^{\mathrm{A}}$ & $149.15^{\mathrm{A}}$ & $157.25^{\mathrm{A}}$ & $82.05^{\mathrm{A}}$ & $79.55^{A}$ & $53.45^{\mathrm{A}}$ & $50.15^{A}$ \\
\hline 3으 Di & $1938^{A B}$ & $1824^{\mathrm{A}}$ & $28.40^{\mathrm{A}}$ & $32.8^{\mathrm{A}}$ & $15.40^{\mathrm{A}}$ & $15.28^{\mathrm{A}}$ & $147.98^{\mathrm{A}}$ & $194.07^{\mathrm{A}}$ & $79.40^{\mathrm{A}}$ & $91.70^{\mathrm{A}}$ & $55.29^{A}$ & $46.74^{\mathrm{A}}$ \\
\hline 5ㅇpi & $1300^{A}$ & $1856^{A}$ & $23.00^{\mathrm{A}}$ & $30.0^{A}$ & * & $*$ & $186.07^{\mathrm{A}}$ & $161.71^{\mathrm{A}}$ & * & * & * & * \\
\hline 7으 Dpi & $1722^{A B}$ & $2436^{A}$ & $28.80^{\mathrm{A}}$ & $30.4^{\mathrm{A}}$ & $12.50^{\mathrm{A}}$ & * & $169.62^{A}$ & $125.88^{A}$ & $71.57^{\mathrm{A}}$ & * & $41.94^{A}$ & * \\
\hline 9이 Di & $1233^{A}$ & $1858^{\mathrm{A}}$ & $22.33^{A}$ & $30.8^{A}$ & $12.81^{\mathrm{A}}$ & $12.55^{\mathrm{A}}$ & $182.72^{\mathrm{A}}$ & $167.85^{\mathrm{A}}$ & $112.61^{\mathrm{A}}$ & $68.68^{A}$ & $61.35^{\mathrm{A}}$ & $68.68^{A}$ \\
\hline $12^{\circ} \mathrm{Dpi}$ & * & $2976^{B}$ & * & $28.6^{A}$ & * & $15.71^{\mathrm{A}}$ & * & $96.11^{A}$ & * & $52.91^{\mathrm{A}}$ & * & $54.96^{\mathrm{A}}$ \\
\hline $14^{\circ} \mathrm{Dpi}$ & * & $2024^{\mathrm{A}}$ & * & $30.8^{A}$ & * & $9.18^{A}$ & * & $139.74^{\mathrm{A}}$ & * & $41.88^{A}$ & * & $30.11^{A}$ \\
\hline
\end{tabular}

$\mathrm{Rc}=$ Red blood cell counts; $\mathrm{GV}=$ globular volume; $\mathrm{Hb}=$ hemoglobin; $* \mathrm{MCH}=$ Mean corpuscular hemoglobin; $\mathrm{MCHC}=$ mean corpuscular hamoglobin Concentration; MCV = mean corpuscular volume; $*$ = lost sample. Means followed by different letters in the same column indicate significant differences by Tukey's test $(p<0.05)$.

Table 3 - Albumin concentration (Alb) and of aspartate aminotransferase enzyme activity (AST) of birds of brown (B) and white (W) lines experimentally challenged with $S$. Gallinarum Nalr.

\begin{tabular}{|c|c|c|c|c|}
\hline \multirow[t]{2}{*}{ Days post-inoculation (Dpi) } & \multicolumn{2}{|c|}{ Albumin (g/dL) } & \multicolumn{2}{|c|}{ Aspartate aminotransferase (U/L) } \\
\hline & Brown & White & Brown & White \\
\hline - 1 Dpi & $1.59^{\mathrm{A}}$ & $1.60^{\mathrm{A}}$ & $214.4^{\mathrm{A}}$ & $180.72^{\mathrm{A}}$ \\
\hline 1음 & $1.46^{\mathrm{A}}$ & $1.42^{\mathrm{A}}$ & $228.73^{A}$ & $183.35^{\mathrm{A}}$ \\
\hline 3이 Di & $*$ & * & $*$ & $*$ \\
\hline 50 Dpi & $1.10^{\mathrm{A}}$ & $1.27^{\mathrm{A}}$ & $394.14^{\mathrm{B}}$ & $309.32^{\mathrm{B}}$ \\
\hline $70 \mathrm{Dpi}$ & $1.25^{\mathrm{A}}$ & $1.41^{\mathrm{A}}$ & $208.56^{A}$ & $276.40^{B}$ \\
\hline 9이 Di & $1.16^{\mathrm{A}}$ & $0.99^{A}$ & $211.23^{\mathrm{A}}$ & $223.52^{\mathrm{A}}$ \\
\hline $12^{\circ} \mathrm{Dpi}$ & $*$ & $2.32^{\mathrm{B}}$ & $*$ & $299.70^{B}$ \\
\hline 14으 Di & $*$ & $1.73^{\mathrm{A}}$ & $*$ & $267.40^{B}$ \\
\hline
\end{tabular}

$*$ = lost sample. Means followed by different letters in the same column indicate significant differences by Tukey's test $(p<0.05)$. 
Freitas Neto OC, Arroyave W, Alessi AC, Fagliari JJ, Berchieri A
Infection of Commercial Laying Hens with Salmonella Gallinarum: Clinical, Anatomopathological and Haematological Studies
Mean total leukocyte count of semi-heavy birds presented a significant decrease $(p<0.05)$ five days post-infection as compared to the counts before infection, followed by a significant increase $(p<0.05)$ at 7 and 9 days after infection (Table 4). Light birds showed a marked reduction in this parameter on the fifth day post-inoculation, but which was not statistically significant ( $p>0.05$ ), followed by a significant increase $(p<0.05)$ at 12 and 15 days post-infection. Therefore, the behavior of total leukocyte count curves was similar for both strains (Figure 5).

Lymphocytes of semi-heavy birds significantly decreased $(p<0.05)$ seven days post-inoculation as compared to the values seen in the birds of the same group before infection. In light white birds, there was no significant difference $(p>0.05)$ in this parameter throughout the experimental period (Table 4). The other white cell counts (heterophils, eosinophils, monocytes, and basophils) presented no significant differences $(p>0.05)$ in both varieties.

\section{DISCUSSION}

\section{Experiment 1}

The comparatively higher percentage of mortality of semi-heavy birds indicates higher resistance of light birds to fowl typhoid, which is consistent with previous studies (Pomeroy and Nagaraja, 1991; Berchieri et al., 2001). Nevertheless, there was a variation in resistance among white birds, which are generally considered as resistant to this disease. W3 line was more susceptible than the other lines, and presented the highest mortality. The behavior show $\mathrm{n}$ in the present study may be due to organic variations resulting from the genetic selection pressure to which the birds are submitted in order to achieve better performance results, which in the end adversely affects immune responses and resistance to diseases (Swaggerty et al., 2003).

\section{Leckocyte Kinetics}

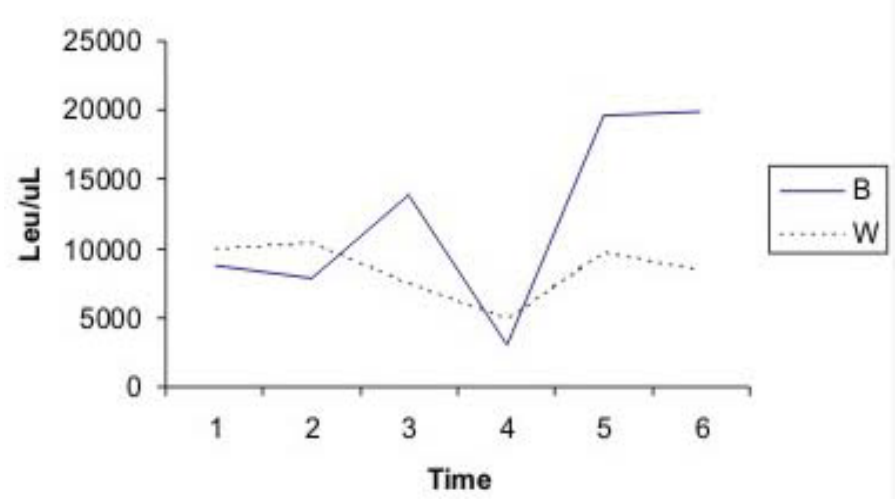

Figure 5 - Graph of leukocyte kinetics of brown (B) and white birds (W) experimentally challenged with SG Nalr.

As to the mortality rate of semi-heavy birds, there was a significant dose-dependent response. The results corroborate an earlier study that showed that disease depends on infecting dose and bird genetic line (Oliveira et al., 2005). On the other hand, Solomon (1968) considers that bird resistance to fowl typhoid depends on the age of the bird at the time of infection.

Fecal shedding was observed seven days postinfection in one semi-heavy bird that was sick. According to Oliveira et al. (2005), although birds do not constantly shed SG, birds that survive the disease may do it.

The results of liver swabs taken 23 days postinfection indicated that SG persisted more markedly in light birds, although there were no clinical signs of the disease. Nevertheless, the presence of bacteria in semi-heavy birds was insignificant. These findings are consistent with a previous study, which suggested that bird lines genetically resistant to fow I typhoid may carry the agent for weeks without showing clinical signs (Berchieri et al., 2000a). This indicates that, although

\begin{tabular}{|c|c|c|c|c|c|c|c|c|c|c|c|c|}
\hline \multirow{3}{*}{$\begin{array}{c}\text { Days post- } \\
\text { Inoculation (Dpi) }\end{array}$} & \multicolumn{10}{|c|}{ White cell counts } & \multirow{2}{*}{\multicolumn{2}{|c|}{ Basophils (\%) }} \\
\hline & \multicolumn{2}{|c|}{ Leucocytes / $\mu \mathrm{L}$} & \multicolumn{2}{|c|}{ Heterophils (\%) } & \multicolumn{2}{|c|}{ Lymphocytes (\%) } & \multicolumn{2}{|c|}{ Monocytes (\%) } & \multicolumn{2}{|c|}{ Eosinphils (\%) } & & \\
\hline & B & $\mathbf{W}$ & B & $\mathbf{W}$ & B & $\mathbf{W}$ & B & $\mathbf{W}$ & B & $\mathbf{W}$ & B & $\mathbf{W}$ \\
\hline - 1 Dpi & $8800^{B}$ & $10000^{\mathrm{A}}$ & $35.8^{A}$ & $44.4^{\mathrm{A}}$ & $59.2^{\mathrm{B}}$ & $51.2^{\mathrm{A}}$ & $2.0^{\mathrm{A}}$ & $2.6^{\mathrm{A}}$ & $1.8^{\mathrm{A}}$ & $0.4^{\mathrm{A}}$ & $1.2^{\mathrm{A}}$ & $1.4^{\mathrm{A}}$ \\
\hline 1이 Di & $7833^{A B}$ & $10375^{A}$ & $33.0^{\mathrm{A}}$ & $53.0^{A}$ & $61.0^{\mathrm{B}}$ & $44.0^{A}$ & $3.3^{\mathrm{A}}$ & $1.5^{\mathrm{A}}$ & $0.7^{\mathrm{A}}$ & $0.25^{A}$ & $2.0^{\mathrm{A}}$ & $1.25^{\mathrm{A}}$ \\
\hline 3ำ Di & $13900^{\mathrm{BC}}$ & $7400^{A}$ & $55.4^{\mathrm{A}}$ & $49.2^{\mathrm{A}}$ & $39.2^{\mathrm{B}}$ & $47.2^{\mathrm{A}}$ & $5.0^{\mathrm{A}}$ & $2.2^{\mathrm{A}}$ & $0.2^{\mathrm{A}}$ & $0.8^{\mathrm{A}}$ & $0.2^{\mathrm{A}}$ & $0.6^{\mathrm{A}}$ \\
\hline 5ㅇ Dpi & $3000^{A}$ & $4833^{A}$ & $56.0^{A}$ & $43.7^{\mathrm{A}}$ & $40.05^{B}$ & $51.3^{\mathrm{A}}$ & $2.25^{\mathrm{A}}$ & $3.0^{\mathrm{A}}$ & $0.5^{\mathrm{A}}$ & $1.0^{\mathrm{A}}$ & 0.75 & $1.0^{\mathrm{A}}$ \\
\hline 70 Dpi & $19600^{C}$ & $9700^{A}$ & $58.0^{A}$ & $44.0^{A}$ & $34.4^{\mathrm{A}}$ & $50^{A}$ & $4.0^{A}$ & $3.4^{\mathrm{A}}$ & $1.8^{\mathrm{A}}$ & $0.8^{\mathrm{A}}$ & $1.8^{\mathrm{A}}$ & $1.8^{\mathrm{A}}$ \\
\hline 9o Dpi & $19833^{C}$ & $8400^{A}$ & $40.3^{A}$ & $47.8^{A}$ & $56.0^{B}$ & $47.2^{A}$ & $3.3^{\mathrm{A}}$ & $3.6^{\mathrm{A}}$ & $0.3^{\mathrm{A}}$ & $0.6^{\mathrm{A}}$ & $0.0^{\mathrm{A}}$ & $0.8^{\mathrm{A}}$ \\
\hline 12으 Di & $*$ & $13700^{\mathrm{B}}$ & $*$ & $47.0^{A}$ & $*$ & $48.8^{A}$ & $*$ & $2.2^{\mathrm{A}}$ & $*$ & $1.4^{\mathrm{A}}$ & $*$ & $0.6^{\mathrm{A}}$ \\
\hline $14^{\circ} \mathrm{Dpi}$ & $*$ & $16100^{B}$ & * & $40.8^{A}$ & $*$ & $55.0^{A}$ & $*$ & $3.0^{\mathrm{A}}$ & $*$ & $0.6^{\mathrm{A}}$ & $*$ & $0.6^{\mathrm{A}}$ \\
\hline
\end{tabular}

$*$ = lost sample. Means followed by different letters in the same column indicate significant differences by Tukey's test $(p<0.05)$. 
Freitas Neto OC, Arroyave W, Alessi AC, Fagliari JJ, Berchieri A
Infection of Commercial Laying Hens with Salmonella Gallinarum: Clinical, Anatomopathological and Haematological Studies the birds do not constantly shed SG, in the presence of cannibalism they may become sources of infection of other birds.

In terms of clinical evaluation, light birds showed characteristic signs of fowl typhoid before dying, such as depression, prostration, anorexia, dropped wings, ruffled feathers, and dirty vents. On the other hand, semi-heavy birds died suddenly with no clinical signs. Smith (1955) and Assoku et al. (1970) described similar signs in young broilers three to four days after oral inoculation with $S$. Gallinarum; some inoculated birds developed the acute form of the disease, while others developed the sub-acute form of the disease.

\section{Experiment 2}

In this experiment, no light birds died, whereas semiheavy birds show ed considerable mortality. There were no clinical signs of the disease, and the birds died suddenly. The results are similar to those reported by Assoku et al. (1970), Allan and Duffus (1971), Hall (1991), and Christensen et al. (1996), all of which reported high mortality rates during the development of the disease, which was up to $50 \%$ among birds affected between five and seven days post-infection.

Interestingly, the mortality rate among light birds varied between the first and the second experiment, although the same inoculum concentration was used in both experiments. Whereas mortality was high among these birds in the first experiment, in the second there were no dead birds. This may be explained by the fact that females were used in the first experiment, whereas males were used in the second one. Physiologically, males of domestic birds are usually heavier at hatching as compared to females. Therefore, it may be inferred that the development of the disease would be dose-dependent, under the conditions of this experiment, as previously described (Oliveira et al., 2005).

Gross lesions were restricted to the liver and the spleen of semi-heavy birds. They were larger, and some presented white spots five days after inoculation. The liver was green-yellowish and friable, similar to the lesions described when birds were inoculated with Salmonella Gallinarum (Smith, 1955; Assoku et al., 1970; Pomeroy, 1987; Berchieri, 2000b). There was no evidence of anatomical changes in light birds.

Microscopically, the liver and the heart were the organs that sufferred the greater damage in their cellular structure, considering both bird lines. On the other hand, the kidneys showed a mild degree of lesion, as well as the lungs. Liver lesions were more intense in semi-heavy birds, which presented an irreversible pathological change (hepatocyte necrosis). These lesions were more evident five days after inoculation. Histological liver lesions in light birds were less intense (vacuolar degeneration of hepatocytes). Hall (1991) described histopathological lesions in the liver after experimental infection of birds with SG, such as hepatocyte degeneration around the centrilobular veins that would eventually result in substitution of the parenchyma for conjunctive tissue and an interstitial fibrosis. Later, a process of inflammatory infiltration develops, which is macroscopically evidenced as white spots on the surface of the organ. In the analysis of the histological sections, the heart of both semi-heavy and light birds presented inflammatory infiltration; in the former, it was characterized by the presence of heterophils. Similarly, Smith (1955) described a proliferative cell reaction in this organ, with nodular white masses disseminated in the myocardium.

The results of the present study showed no differences between lines in terms of globular volume $(\mathrm{GV})$, hemoglobin $(\mathrm{Hb})$, mean corpuscular hemoglobin $(\mathrm{MCH})$, mean corpuscular hemoglobin concentration ( $\mathrm{MCHC})$, or mean corpuscular volume (MCM) values caused by experimental infection with SG. There was only a decrease in erythrocytes value in semi-heavy birds at five and nine days post-infection. These findings are different from a previous study, which reported changes in erythrocyte counts during the acute phase of the infection due to an increase in the destruction of these cells (Assoku et al., 1970). As fowl typhoid may develop as an acute, sub-acute, or chronic disease, hematological changes will be different in each situation, and this may explain the differences found in the present study. In sub-acute fowl typhoid, there is no evidence of marked anemia or erythrocyte fragility. There is only a slight reduction in globular volume, which also returns to normal values after the animal has recovered (Pomeroy, 1987).

Total leukocyte counts in semi-heavy birds showed a decrease at five days post-infection (leukopenia) relative to the values determined before infection. At seven days post infection, there was an increase that indicated leukocytosis. Nevertheless, light birds that showed a biologically marked and non-significant decrease in leukocyte counts also presented leukocytosis after the $12^{\text {th }}$ day post-infection. Assoku et al.(1970), Allan and Duffus (1971), and Cardoso et al. (2003) reported similar increases using SG inoculation under experimental conditions. The decrease in total leukocyte counts may be explained 
Freitas Neto OC, Arroyave W, Alessi AC, Fagliari JJ, Berchieri A
Infection of Commercial Laying Hens with Salmonella Gallinarum: Clinical, Anatomopathological and Haematological Studies by the cytolytic effect of Salmonella on leukocytes during the initial infection (Lam and M unn, 2002). It may also be due to the high susceptibility of these cells to the cytopathic effect of SG lipopolysaccharides (Buxton and Allan, 1963). It is interesting to note that the behavior of leukocyte kinetics shown during the initial infection with Salmonella Gallinarum in the present study, both in semi-heavy and light birds (Figure 5), has not been described in the retrieved studies with birds, despite being described in mammals (Santos et al., 2002).

Lymphocyte percentage values in semi-heavy birds decreased (lymphopenia) after the $7^{\text {th }}$ day post-infection as compared to the same group of birds before being inoculated. Values increased after the $9^{\text {th }}$ day postinfection up to normal values, similar to those before inoculation. In the light birds, leukocyte numbers varied within normal ranges during the experiment. In a similar study, Allan and Duffus (1971) found no changes in lymphocyte counts during the course of fowl typhoid. On the other hand, Assoku et al. (1970) worked with SG in birds, and found lymphocyte counts lower than normal values. Lymphopenia is common in acute inflammatory responses, because inflammatory mediators stimulate the migration of heterophils and lymphocytes from the blood and lymphoid tissues to the inflammation site (Jain, 1993).

The marked increase in heterophil counts observed after the $5^{\text {th }}$ day post-infection was not statistically significant. How ever, leukocytosis was previously reported caused by an increase in heterophils up to five times higher than before inoculation (Assoku et al., 1970). Leukocytosis is usually due to heterophilia, and common causes are general infections due to septicemias caused by infectious agents, such as salmonella (M orgulis, 2002).

Monocyte, eosinophil, and basophil percentage values in birds both susceptible and resistant to fowl typhoid, in the present study, showed no relevant changes, and were consistent with previous reports (Allan and Duffus, 1971; Cardoso et al., 2003).

Although serum albumin levels were normal in both groups, they were lower in susceptible birds five days post-inoculation as compared to healthy birds of the same strain.

There was an increase in the activity of aspartate aminotransferase (AST) in semi-heavy birds five days post-inoculation as compared to the mean value in birds of the same group, before being infected, and the values decreased after the $7^{\text {th }}$ day post-inoculation. Light birds showed an increase in mean enzyme value at $5,7,12$, and 14 days post-inoculation.
In this study, when the values of albumin and AST in semi-heavy birds are compared with the degree of liver lesion at five-days post-inoculation, a coincidence is observed among highest lesion score (multifocal necrosis), higher AST levels, and lower albumin levels in these birds. This may be interpreted as an incapacity of the liver to synthesize protein due to the lesion intensity, microscopically evidenced by hepatomegaly and loss of protein in the affected kidney. Therefore, the damage in the glomerular filtration barrier may result in the presence of plasma proteins in the urine; in addition, inflammation of the renal parenchyma or epithelial damage of the tubules may cause loss of protein to the urine (Reldford and Lees, 1996).

In conclusion, the absence of a similar behavior in the response of the defense system of the birds in the presence of fow I typhoid makes it difficult to understand the relationship between Salmonella Gallinarum and affected birds. Similarly, the observations of the present study raise questions regarding the pathogenesis of fow I typhoid. Further studies are necessary to elucidate the relationship between birds and this bacterium.

\section{REFERENCES}

Allan D, Duffus W. The immunophatology in fowls (Gallus domesticus) of acute and subacute Salmonella Gallinarum infection. Research in Veterinary Science 1971; 12:140-151.

Assoku R, Buxton A, Penhale W. Haematological changes in acute experimental Salmonella Gallinarum infection in chickens. Journal of Comparative Pathology 1970; 80:473-485

Behmer O, Tolosa E, Freitas A. Técnicas para histologia normal e patológica. São Paulo: Editora da Universidade de São Paulo; 1976.

Berchieri Jr A. Salmoneloses aviárias. In: Berchieri Junior A, Macari M.editors. Doenças das aves. Campinas: Facta; 2000. p. 185-196

Berchieri Jr A, M urphy A, Marston K, Barrow PA. Observations on the persistence and vertical transmission of Salmonella enterica sorovars Gallinarum and Pollorum in chickens: effect of bacterial and host genetic background. Avian Pathology 2001; 30(3):221-231.

Berchieri Jr A, Oliveira G, Pinheiro I, Barrow PA. Experimental Salmonella Gallinarum infection in light laying hen lines. Brazilian Journal of Microbiology 2000; 31:50-52.

Buxton A. Pathological changes in the blood of chickens infected with Salmonella Gallinarum. The Journal of Comparative Pathology and Therapeutics 1960; 70:308-325.

Buxton A, Allan D. Studies on immunity and pathogenesis of salmonellosis. I. Antigen-antibody reactions on circulating leucocytes of chickens infected with Salmonella Gallinarum. Immunolo gy 1963; 6:520-529. 


\section{Freitas Neto OC, Arroyave W, Alessi AC, Fagliari JJ, Berchieri A}

Infection of Commercial Laying Hens with Salmonella Gallinarum: Clinical, Anatomopathological and Haematological Studies
Cardoso A, Castro A, Tessari E. Estudo hematológico em aves inoculadas com Salmonella Gallinarum. Arquivos do Instituto Biológico 2003; 70(1):35-42.

Christensen JP, Barrow PA, OIsen JE, Poulsen JS, Bisgaard. Correlation between viable counts of Salmonella Gallinarum in spleen and liver and the development of anaemia in chickens as seen in experimental fowl typhoid. Avian Pathology 1996; 25(4): 769-783.

Hall W. Fow I Typhoid. En: Biester HE, Schwarte HL editors. Diseases of poultry. lowa: State University Press; 1991. p. 87-99.

Jain NC. Essentials of veterinary hematology. Philadelphia: Lea \& Febiger; 1993. p. 365-372.

Ji-Dong JIN, Dong-Seok LEE, Eun-Kyng S HIN, Rose JUNG and TaeWook HAHH. Molecular Typing by Random Amplification of Polymorphic DNA (RAPD) and detection of virulence genes of Salmonella enterica subspecies enterica serovar Gallinarum biovar Gallinarum. Journal Veterinary M edicine Science 2006; 68(12): 1321-1326.

Lam KM, M unn R. The cytolytic effects of Salmonella enterica sorovar Typhimutium on chicken heterophils. Avian Pathology 2002; 31: 277-283.

M orgulis M. Imunologia aplicada. In: M acari M , Furlan RL, Gonzalez E editors. Fisiologia aviária aplicada a frangos de corte. Jaboticabal: FUNEP/ UNESP; 2002. p. 375-429.

Oliveira GH, Fernandes AC, Berchieri J r A. Experimental infection of laying hen with Salmonella Gallinarum. Brazilian Journal of Microbiology 2005; 36:51-56.

Pomeroy B. Fowl Typhoid. In: Hofstad MD, Calnek CF, Helmbolt WM, Reid HW, Yoder JR editors. Diseases of poultry. Ames: lowa, State University Press; 1987. p. 100-116.

Prince WR, Garren HW. An investigation of the resistance of White leghorn chicks to Salmonella Gallinarum. Poultry Science 1966; 45(6): 1149-1153.

Qureshi MA. Role of Macrophages in Avian Health and Disease. Poultry Science 1998; 77(7):978-982.

Relford RL, Lees GE. Nephrotic syndrome in dogs: diagnosis and treatment. Compendium Continuing Education Practice Veterinary 1996; 18:279-292.

Smith H. Observations on experimental fowl tiphoid. Journal of Comparative Pathology 1955; 65:37-57.

Solomon JB. Immunity to Salmonella Gallinarum during Ontogeny of chicken. I. Onset of resistance to infection; the minor roll of opsonins. Immunology 1968; 15:197-206.

Santos RL, Zhang S, Tsolis R, Baumher AJ, Adams G. Haematologic and serum biochemical changes in Salmonella sorovar Typhimurium- infected calves. American Journal of Veterinary Research 2002; 63:1145-1150.
Shivraprasad HL. Pullorum disease and fowl typhoid. Revue Scientifique et Technique Office International Epizooties 2000; 19: 405-424.

Swaggerty CL, Pevzner IY, Lowry VK, Farnellm B, Kogut M H. Functional comparison of heterofils isolated from commercial broiler chickens. Avian Pathology 2003; 32:95-102.

Wigley P, Hulme SD, Bunstead N, Barrow PA. In vivo and vitro studies of genetic resistence to systemic salmonellosis in the chicken encoded by SAL 1 locus. Microbes and Infection 2002; 4:11111120 . 